\title{
The Characterization of Castor (Ricinus communis L.) Genotypes for Morphological Traits
}

\author{
B.A. Chaudhari*, M.P. Patel, J.A. Patel, R.R. Makwana, A.M. Patel and M.K. Patel
}

Department of Genetics and Plant breeding, C. P. College of Agriculture, Sardarkrushinagar Dantiwada Agricultural University, Sardarkrushinagar-385506 (Gujarat), India

*Corresponding author

\section{A B S T R A C T}

\begin{tabular}{|c|}
\hline Keywords \\
\hline $\begin{array}{l}\text { Castor, } \\
\text { Morphological traits } \\
\text { (Qualitative } \\
\text { characters) }\end{array}$ \\
\hline Article Info \\
\hline $\begin{array}{l}\text { Accepted: } \\
26 \text { April } 2019 \\
\text { Available Online: } \\
10 \text { May } 2019\end{array}$ \\
\hline
\end{tabular}

\section{Introduction}

Castor (Ricinus communis L. $2 \mathrm{n}=2 \mathrm{X}=20$ ) resides to mono specific genus Ricinus of Euphorbiaceae family and one of the most important non-edible oilseed crop (Chaudhari et al., 2019). It has cross pollination up to the extent of 50 per cent due to its monoecious nature.

Morphological characters like stem color, bloom, seed shape, plant type, leaf shape, types of internodes, spike shape, inflorescence spike shape, seed coat color, branching habits, spike types and capsule type are important markers used for distinctness, uniformity and stability (DUS) tests in castor under different environments (Lavanya and Gopinath, 2008).

Morphological characterization of seed, seedling and plant would generally be considered for varietal identification. Introduction of Plant Variety Protection under General Agreement on Trade and Tariff (GATT) necessitated the need is precise genotypic characterization with clear Distinctiveness (D), Uniformity (U) and Stability (S). The concept of DUS was fundamental for the characterization of the variety as a unique creation. It is essential to 
secure Plant Breeder's Rights (PBR's) and it also generates official description of a variety. Information on DUS characters generated in castor is not documented until now. Hence, there is a need to characterize castor genotypes.

\section{Materials and Methods}

The main objective of the investigation was to characterize the castor germplasm to assess their potential to contribute to future crop improvement programmes. The twenty six castor genotypes including advanced parental lines and hybrids were evaluated at CastorMustard Research Station, Sardarkrushinagar Dantiwada Agricultural University, Sardarkrushinagar in Randomized Block Design in three replications with inter and intra row spacing of $120 \times 60 \mathrm{~cm}$. Need based agronomic and plant protection measures were taken up for good crop growth. Data was collected at various growth stages of castor plant.

\section{Results and Discussion}

Three types of stem colors were observed viz., green, mahogany and red. Five genotypes and three hybrids had green stem color, while fifteen (7 genotypes +8 hybrids) had mahogany stem colour, remaining three genotypes had red stem color (Table 1). Bloom or waxy coating in castor is an important morphological marker and serves as a natural protection against drought, cold, jassids etc., (Lavanya and Gopinath, 2008). Based on presence of bloom on combination of plant parts, genotypes in castor were usually classified as single bloom (stem + petiole + capsule stalks), double bloom (stem + petiole + capsule + lower side of the leaf) and triple bloom (all the above parts + upper side of the leaf).The sixteen genotypes (7 genotypes +9 hybrids) had triple bloom while, nine genotypes ( 7 genotypes +2 hybrids) had double bloom and JI-65 had zero bloom. Seven hybrids and twelve genotypes had spiny capsule, while four had semi spiny and GEETA, 48-1 and SKI-215 had non spiny. Out of 26 genotypes, 23 genotypes had elongated type of internodes, whereas three genotypes had condensed type of internodes. Three types of leaf shape, flat, semi-deep and deep-cup were observed. Twenty three genotypes had flat leaf shaped, remaining two genotypes viz., VP-1 and SKP-84 had deepcup leaf shaped and GCH-7 had semi-deep leaf shaped.

In spike shape all the twenty-six genotypes had conical spike shape. Four types of spike were observed like loose, semi-loose, semicompact and compact. Genotypes, GNCH-1, GEETA, 48-1 and JI-96 had loose type spike whereas; seven genotypes had semi-loose spike and five genotypes had semi-compact of spike whereas, ten genotypes had compact spike type. In branching habit, out of 26 genotypes, 24 genotypes had divergent branching habit while, VP-1 and SKP-84 had convergent branching habit. Three types of inflorescence spike were observed; monoecious, interspersed and pistillate. Out of 26 genotypes nineteen genotypes had interspersed inflorescence spike, while GAUCH-1, JI-96 and VI-9 had monoecious inflorescence spike. Remaining four genotypes viz., VP-1, GEETA, SKP-84 and JP-65 had pistillate types of inflorescence. The photographs of all the qualitative characters have been shown in the figure 1-4.

Twenty six genotypes were categorized in to three different groups as: dwarf plant type viz., (VP-1 and SKP-84), medium plant type (viz., GAUCH-1, GCH-2, GCH-4, GCH-6, GCH-7, SHB-1005, SHB-1018, SHB-1019, SHB-1029, GNCH-1, JP-65, VI-9, SKI-352, SKI-370, SKI-372, SKI-373, DCS-94) and tall plant type (GCH-5, GEETA, JI-35, 48-1, SH-72, JI-96 and SKI-215). In seed shape 24 
genotypes had oval seed shape, while genotype GEETA and JI-35 had round seed shape. Two types of seed coat color were observed; dark brown and light brown. Genotypes GAUCH-1, GCH-2, GCH-4, GCH-5, SHB-1005, SHB-1018, SHB-1019, SHB-1029, GNCH-1, VP-1, GEETA, JP-65, SKI-84, VI-9, JI-35, SH-72 JI-96, SKI-215, SKI-370, SKI-373 and DCS-94 had dark brown seed coat color and remaining genotypes GCH-6, GCH-7, 48-1, SKI-352 and SKI-372 had light brown seed coat color. The results are in accordance with findings of Solanki and Joshi (2001), Lavanya and Gopinath (2008), Bhanu (2009), Elena and Edilyng (2009), Gourishankar et al., (2010), Sakure et al., (2010), Gupta and Aggarwal (2012), Rao (2014) and Rukhsar (2017) which showed that morphological characterization helps in identification of genotypes easily.

The pattern of expression of stem colour indicated that mahogany stem colour was controlled by nuclear genes and dominant in nature over green and red. Crosses of red $x$ green, green $x$ mahogany and mahogany $\times$ mahogany stem color, all $F_{1}$ 's were mahogany whereas, in case of green $\times$ green stem color all $F_{1}$ 's produced green stem color, but in case of red $\times$ mahogany, all $F_{1}$ 's were green in color. In most of the genotypes, mahogany stem was observed with varying range from green to red which could be due to different genetic background of parental genotypes influencing the expression of gene/s. With regards to bloom, most of the genotypes were triple bloom in nature, which indicated its dominant nature. The triple bloom nature was dominant over double bloom and zero bloom; whereas, double bloom nature was dominant over zero bloom.

Regarding capsule type, when the crosses were made between spiny $\times$ non spiny, all $F_{1}$ 's were semi spiny. It is the indication of spiny capsule type nature was co-dominant over non-spiny capsule. Dwarf plant type had a condensed internode. When condensed parents crossed with elongated parents, all the $\mathrm{F}_{1}$ 's were elongated internodes. This revealed that elongated internodes were dominant over condensed internodes. It was also observed that all dwarf plants i.e. condensed internodes had deep cup leaves and elongated internodes had flat leave shape indicating pleiotropic effect or tight linkage of genes governing these two traits. The cup shaped leaf was determined by a single recessive gene. Crosses of deep cup $\times$ deep cup and flat $\times$ flat cup, all $F_{1}$ 's were deep cup and flat cup leaf, respectively. However, deep cup $\times$ flat cup parent produced flat cup except, cross SKP-84 $\times$ SKI-2015 (GCH-7). The results were not sufficient to interpret; this could be because of quasi quantitative character.

The conical $\times$ conical and cylindrical $\times$ cylindrical crosses produced conical and cylindrical spike shape, respectively. The results were not sufficient to interpret; this could be because of quasi quantitative character. An expression of spike type showed more than one class of $\mathrm{F}_{1}$ 's from all the genotypes, which indicated involvement of more than one gene, and epistatic type of gene interaction for the inheritance of the character and expression of the character was also influenced by different genetic background of parents. When convergent $\times$ divergent parent was crossed, all the $F_{1}$ 's produced divergent branching habit. This revealed that divergent branching pattern was dominant over convergent branching pattern. Regarding inflorescence spike types, in most of the genotypes inflorescence spike types nature was observed, which indicated its dominant nature. The interspersed inflorescence spike type's nature was dominant over monoecious and pistillate whereas, monoecious nature was dominant over pistillate. 
Table.1 Characterization of different qualitative characters of castor

\begin{tabular}{|c|c|c|c|c|c|c|c|}
\hline \multirow[t]{2}{*}{ Sr. No. } & \multirow[t]{2}{*}{ Genotypes } & Stem color & Bloom & Capsule type & $\begin{array}{c}\text { Types of } \\
\text { internodes }\end{array}$ & Leaf shape & Spike shape \\
\hline & & 1 & 2 & 3 & 4 & 5 & 6 \\
\hline 1 & GAUCH-1 & Green & Triple & Spiny & Elongated & Flat & Conical \\
\hline 2 & GCH-2 & Green & Triple & Spiny & Elongated & Flat & Conical \\
\hline 3 & GCH-4 & Mahogany & Triple & Semi-spiny & Elongated & Flat & Conical \\
\hline 4 & GCH-5 & Mahogany & Double & Semi-spiny & Elongated & Flat & Conical \\
\hline 5 & GCH-6 & Green & Double & Spiny & Elongated & Flat & Conical \\
\hline 6 & GCH-7 & Mahogany & Triple & Semi-spiny & Elongated & Semi cup & Conical \\
\hline 7 & SHB-1005 & Mahogany & Triple & Spiny & Condensed & Flat & Conical \\
\hline 8 & SHB-1018 & Mahogany & Triple & Semi-spiny & Elongated & Flat & Conical \\
\hline 9 & SHB-1019 & Mahogany & Triple & Spiny & Elongated & Flat & Conical \\
\hline 10 & SHB-1029 & Mahogany & Triple & Spiny & Elongated & Flat & Conical \\
\hline 11 & GNCH-1 & Mahogany & Triple & Spiny & Elongated & Flat & Conical \\
\hline 12 & VP-1 & Green & Triple & Spiny & Condensed & Deep cup & Conical \\
\hline 13 & GEETA & Red & Double & Non spiny & Elongated & Flat & Conical \\
\hline 14 & JP-65 & Red & Zero & Spiny & Elongated & Flat & Conical \\
\hline 15 & SKP-84 & Mahogany & Triple & Spiny & Condensed & Deep cup & Conical \\
\hline 16 & VI-9 & Green & Double & Spiny & Elongated & Flat & Conical \\
\hline 17 & JI-35 & Green & Double & Spiny & Elongated & Flat & Conical \\
\hline 18 & $48-1$ & Red & Double & Non-spiny & Elongated & Flat & Conical \\
\hline 19 & SH-72 & Green & Double & Spiny & Elongated & Flat & Conical \\
\hline 20 & JI-96 & Mahogany & Triple & Spiny & Elongated & Flat & Conical \\
\hline 21 & SKI-215 & Mahogany & Double & Non-spiny & Elongated & Flat & Conical \\
\hline 22 & SKI-352 & Mahogany & Triple & Spiny & Elongated & Flat & Conical \\
\hline 23 & SKI-370 & Mahogany & Triple & Spiny & Elongated & Flat & Conical \\
\hline 24 & SKI-372 & Mahogany & Triple & Spiny & Elongated & Flat & Conical \\
\hline 25 & SKI-373 & Mahogany & Double & Spiny & Elongated & Flat & Conical \\
\hline 26 & DCS-94 & Green & Triple & Spiny & Elongated & Flat & Conical \\
\hline
\end{tabular}


Table 1 (Contd.)

\begin{tabular}{|c|c|c|c|c|c|c|c|}
\hline \multirow[t]{2}{*}{$\begin{array}{l}\text { Sr. } \\
\text { No. }\end{array}$} & \multirow[t]{2}{*}{ Genotypes } & Spike type & Branching habit & $\begin{array}{l}\text { Inflorescence } \\
\text { spike types }\end{array}$ & Plant type & Seed shape & Seed coat color \\
\hline & & 7 & 8 & 9 & 10 & 11 & 12 \\
\hline 1 & GAUCH-1 & Compact & Divergent & Monoecious & Medium & Oval & Dark brown \\
\hline 2 & GCH-2 & Compact & Divergent & Interspersed & Medium & Oval & Dark brown \\
\hline 3 & GCH-4 & Semi- compact & Divergent & Interspersed & Medium & Oval & Dark brown \\
\hline 4 & GCH-5 & Semi-compact & Divergent & Interspersed & Tall & Oval & Dark brown \\
\hline 5 & GCH-6 & Compact & Divergent & Interspersed & Medium & Oval & Light brown \\
\hline 6 & GCH-7 & Semi-compact & Divergent & Interspersed & Medium & Oval & Light brown \\
\hline 7 & SHB-1005 & Semi-loose & Divergent & Interspersed & Medium & Oval & Dark brown \\
\hline 8 & SHB-1018 & Semi-loose & Divergent & Interspersed & Medium & Oval & Dark brown \\
\hline 9 & SHB-1019 & Semi-loose & Divergent & Interspersed & Medium & Oval & Dark brown \\
\hline 10 & SHB-1029 & Semi-loose & Divergent & Interspersed & Medium & Oval & Dark brown \\
\hline 11 & GNCH-1 & Loose & Divergent & Interspersed & Medium & Oval & Dark brown \\
\hline 12 & VP-1 & Compact & Convergent & Pistillate & Dwarf & Oval & Dark brown \\
\hline 13 & GEETA & Loose & Divergent & Pistillate & Tall & Round & Dark brown \\
\hline 14 & JP-65 & Compact & Divergent & Pistillate & Medium & Oval & Dark brown \\
\hline 15 & SKP-84 & Semi-compact & Convergent & Pistillate & Dwarf & Oval & Dark brown \\
\hline 16 & VI-9 & Compact & Divergent & Monoecious & Medium & Oval & Dark brown \\
\hline 17 & JI-35 & Compact & Divergent & Interspersed & Tall & Round & Dark brown \\
\hline 18 & $48-1$ & Loose & Divergent & Interspersed & Tall & Oval & Light brown \\
\hline 19 & SH-72 & Compact & Divergent & Interspersed & Tall & Oval & Dark brown \\
\hline 20 & JI-96 & Loose & Divergent & Monoecious & Tall & Oval & Dark brown \\
\hline 21 & SKI-215 & Semi-compact & Divergent & Interspersed & Tall & Oval & Dark brown \\
\hline 22 & SKI-352 & Compact & Divergent & Interspersed & Medium & Oval & Light brown \\
\hline 23 & SKI-370 & Compact & Divergent & Interspersed & Medium & Oval & Dark brown \\
\hline 24 & SKI-372 & Semi-loose & Divergent & Interspersed & Medium & Oval & Light brown \\
\hline 25 & SKI-373 & Semi-loose & Divergent & Interspersed & Medium & Oval & Dark brown \\
\hline 26 & DCS-94 & Semi-loose & Divergent & Interspersed & Medium & Oval & Dark brown \\
\hline
\end{tabular}


Fig.1 Different qualitative characters of castor

1. Stem Colour

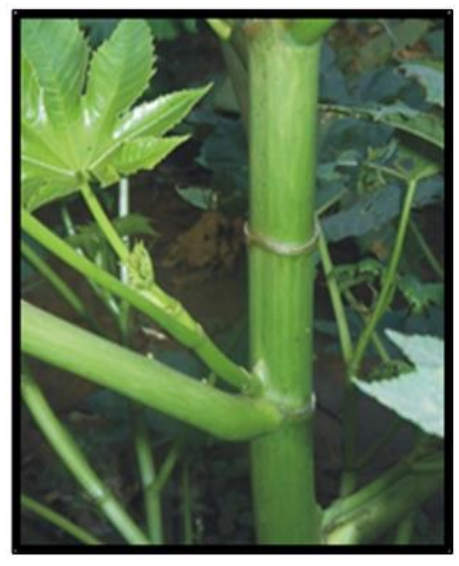

Green

2. Bloom

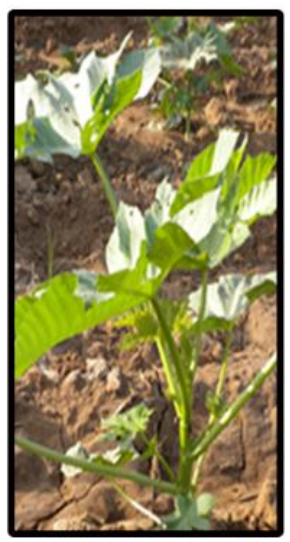

Zero

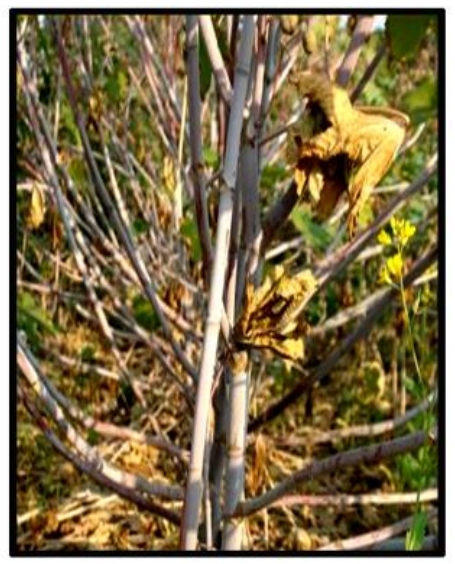

Mahogany

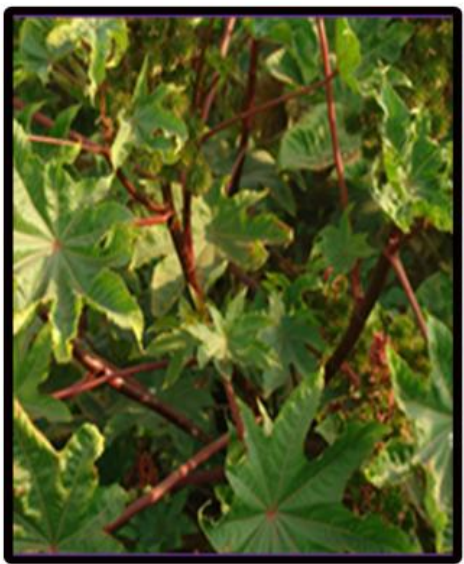

Red

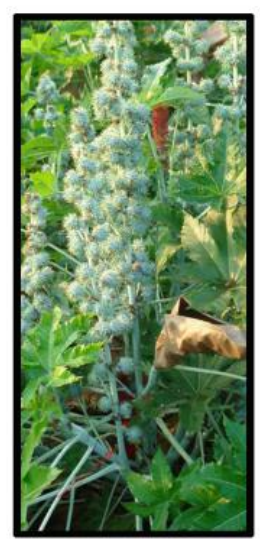

Single

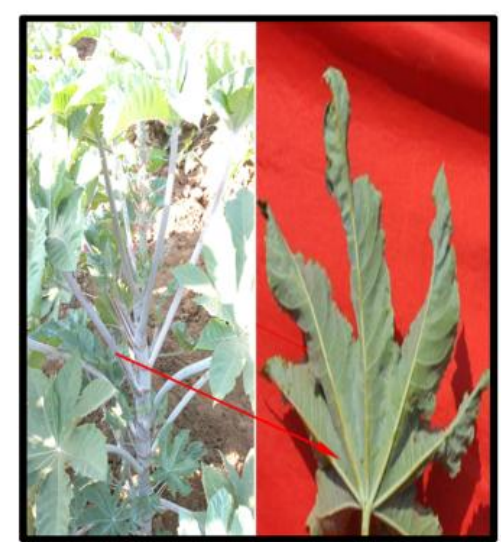

Double

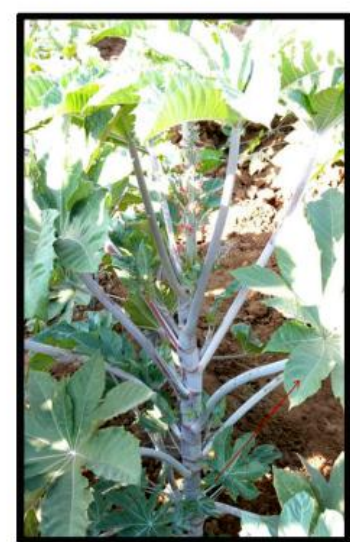

Triple

3. Capsule type

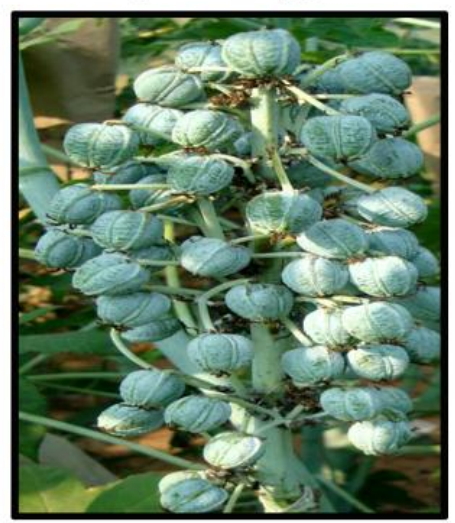

Non-Spiny

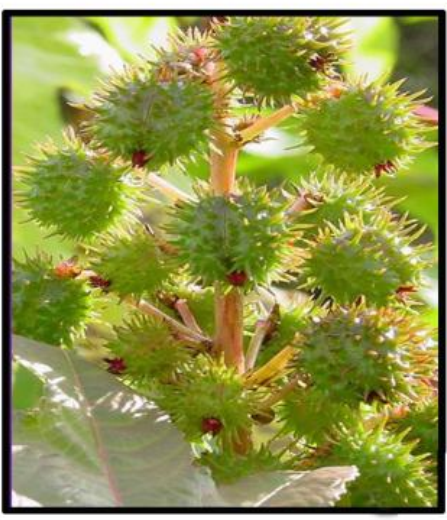

Semi-Spiny

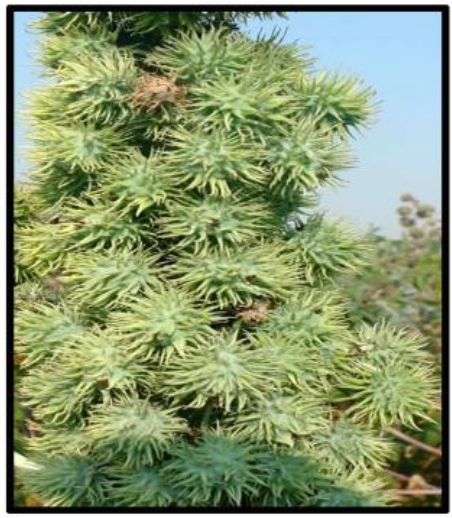

Spiny 
Fig.2 Different qualitative characters of castor

\section{Types Of Internode}

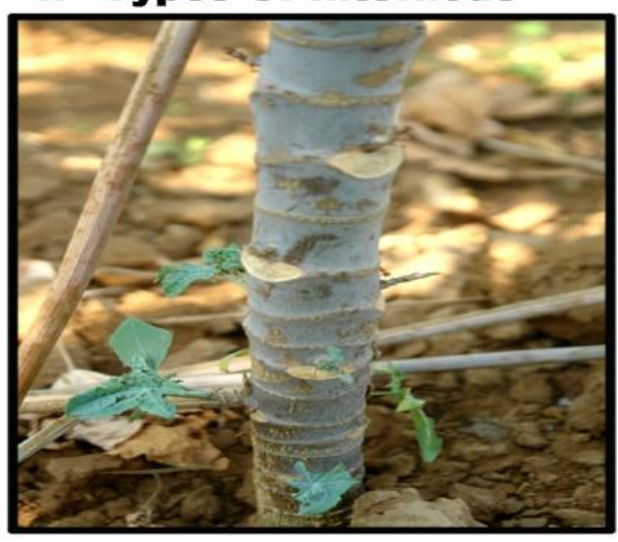

Condensed

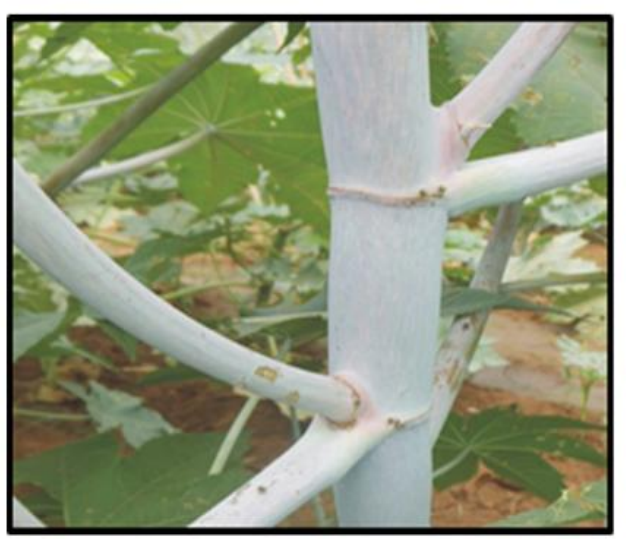

Elongated

\section{Leaf Shape}

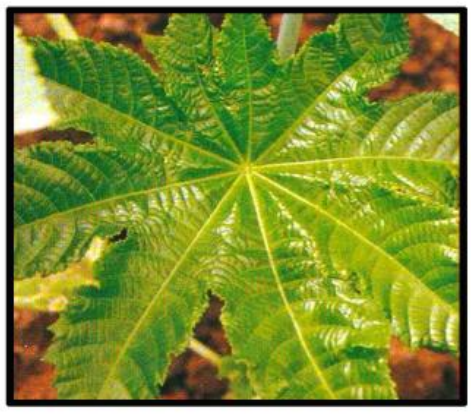

Flat

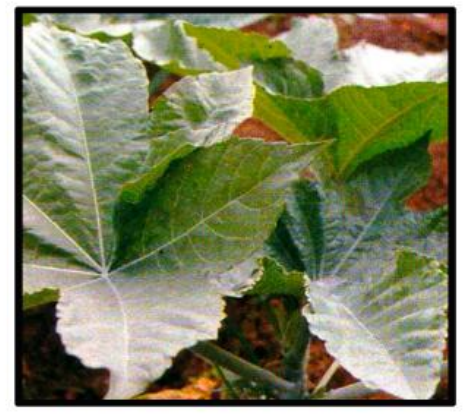

Semi-cup

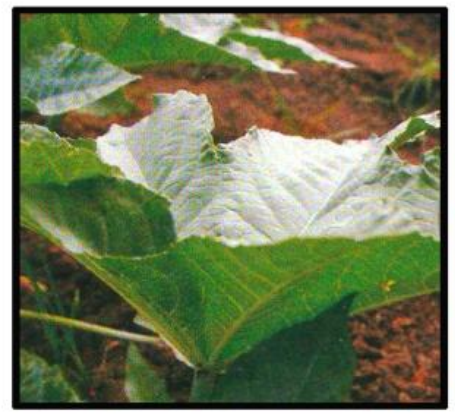

Deep-cup

\section{Spike Shape}

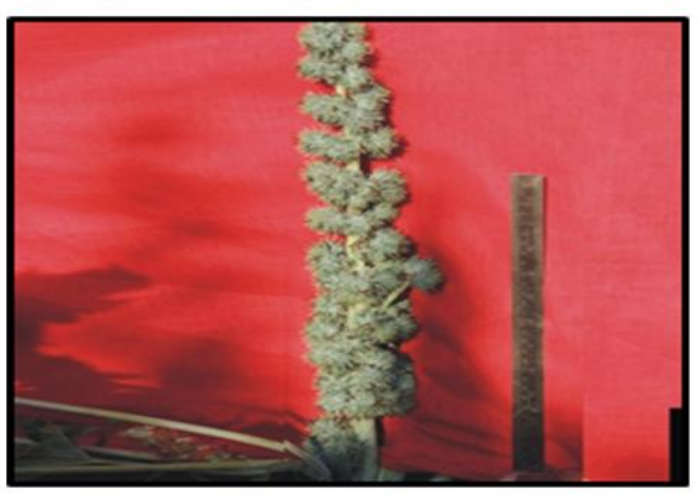

Cylindrical

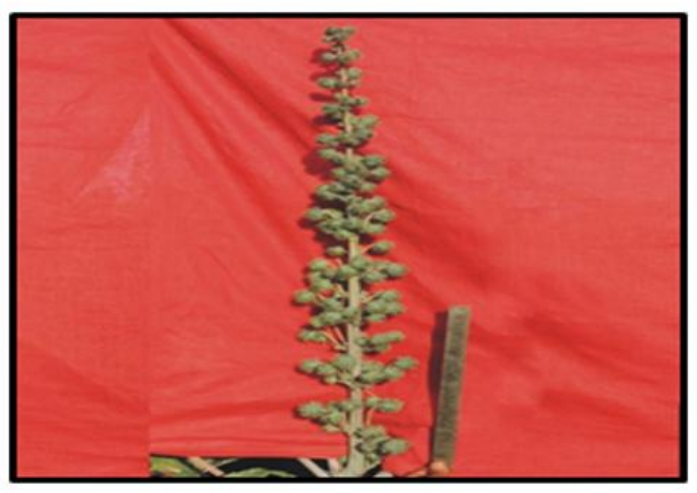

Conical 


\section{Spike types}

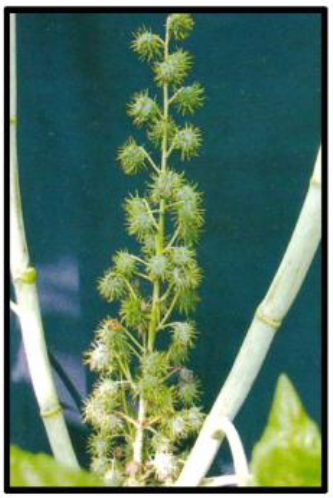

Loose

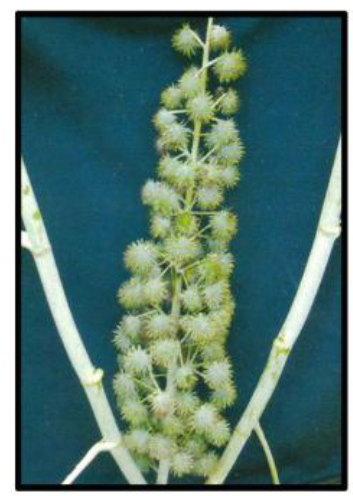

Semi-loose

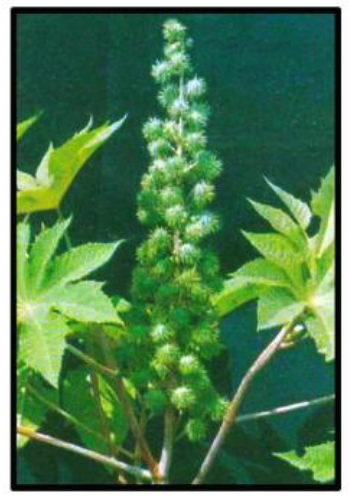

Semi-compact

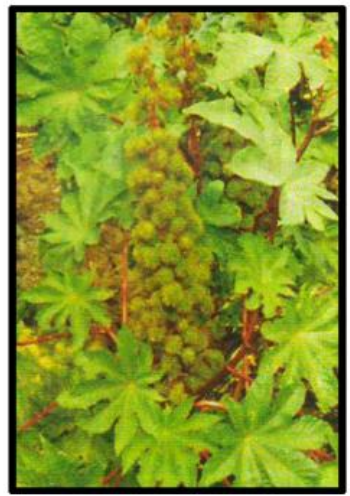

Compact

\section{Branching Pattern}

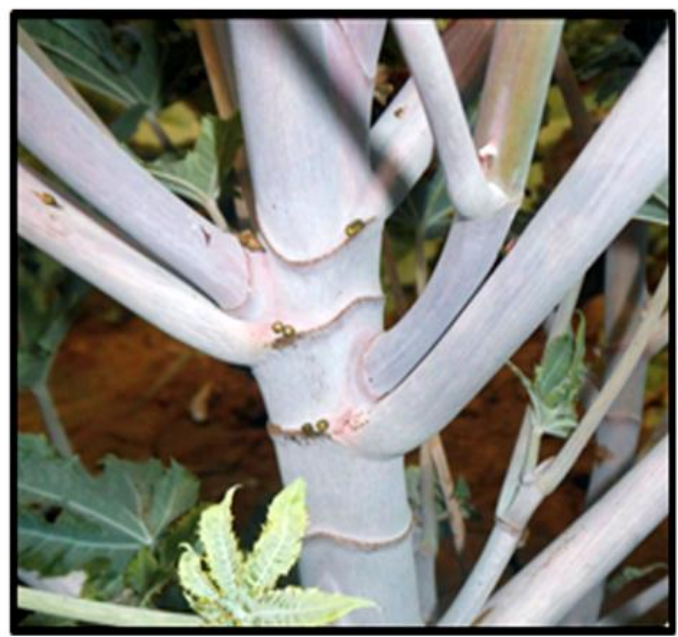

Convergent

\section{Inflorescence spike types}

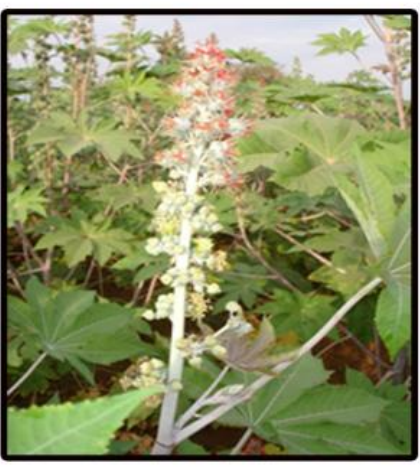

Monoecious

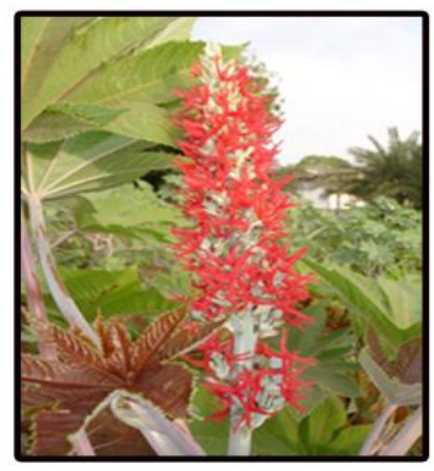

Pistillate

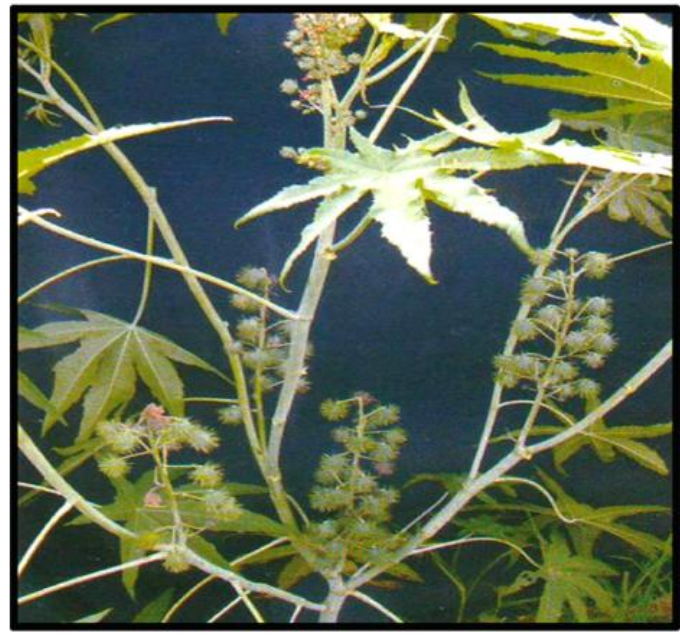

Divergent

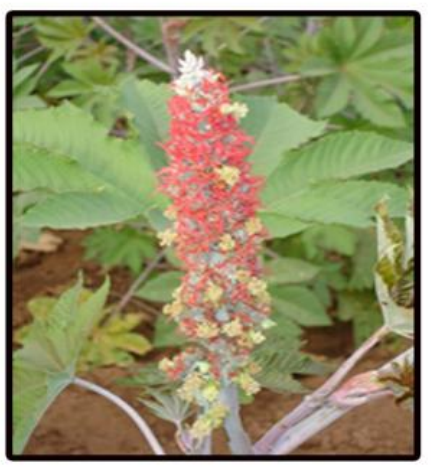

Interspersed 
Fig.4 Different qualitative characters of castor

10. Plant type

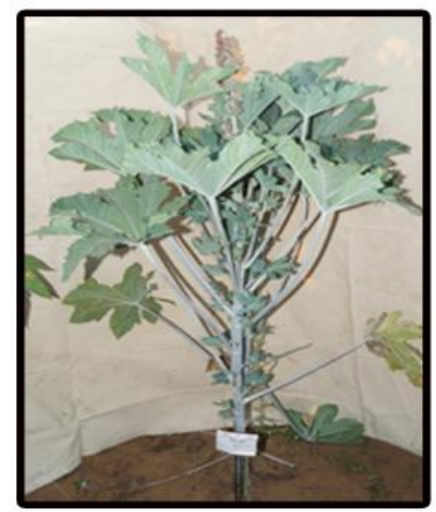

Dwarf

11. Seed shape

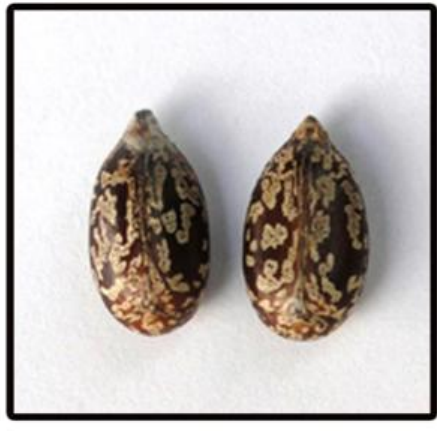

Elongated

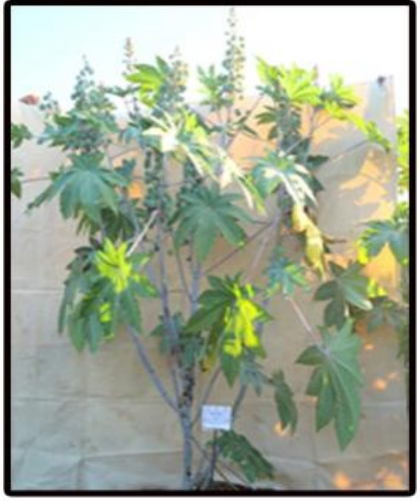

Medium

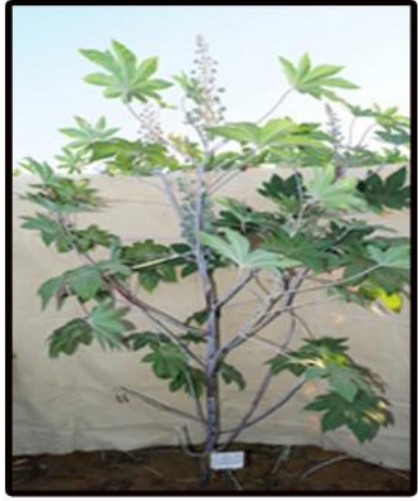

Tall

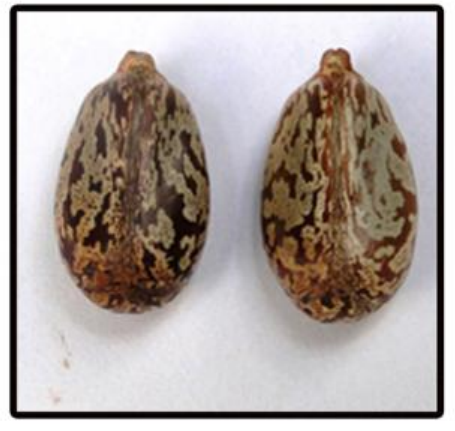

Oval

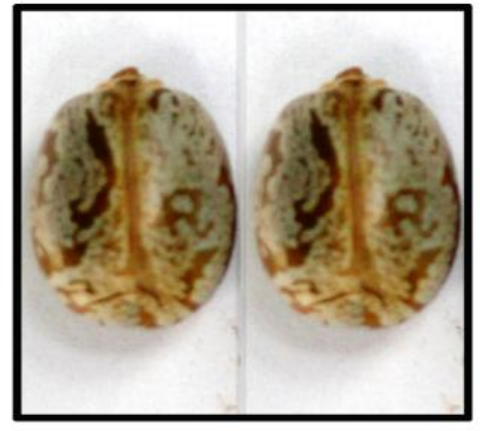

Round

12. Seed coat color

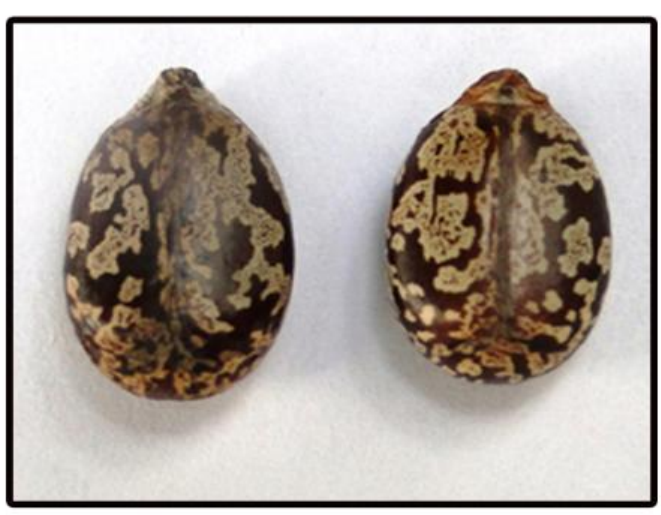

Drak Brown

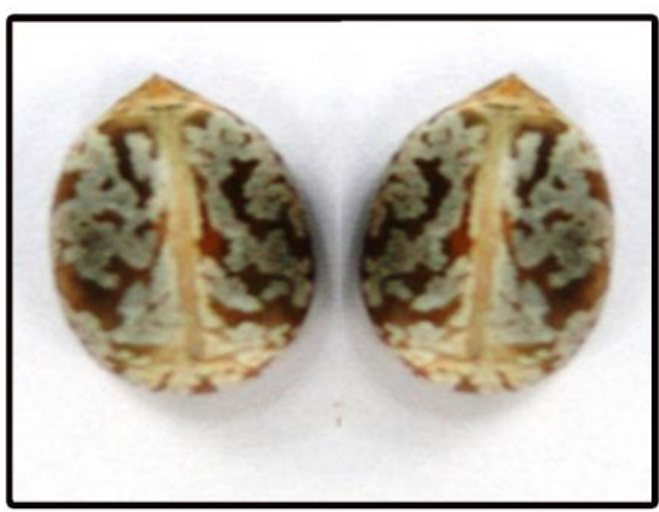

Light Brown 
Dwarf plant stature is desirable for pistillate patent. Crosses between dwarf $\times$ medium plants produced medium plant which indicated that medium plant type was dominant over dwarf plant type. In most of the genotypes and hydrides oval seed shape was observed. The results revealed that oval seed shape was dominant over round seed shape. Dark brown $\times$ dark brown seed color produced all $\mathrm{F}_{1}$ 's with dark brown seed color except, dark brown [JI-65 × JI-96 $(\mathrm{GCH}-6)] \times$ dark brown [SKP-84 $\times$ SKI-215 $(\mathrm{GCH}-7)]$ seed color produced $\mathrm{F}_{1}$ 's with light brown. While in some crosses dark brown $\times$ light brown produced dark brown viz., VP-1 $\times 48-1$ $(\mathrm{GCH}-4)$, SKP-84 $\times$ SKI-352 $($ SHB-1005) and SKP-84 $\times$ SKP-372 (SHB-1019). The results were not sufficient to interpret; this could be because of quasi quantitative character.

In conclusion, morphological characters viz., stem color, bloom, seed shape, plant type, leaf shape, types of internodes, spike shape, inflorescence spike shape, seed coat color, branching habits, spike types and capsule type are important markers to varietal identification and genuineness of variety in castor. They are very important during the development, maintenance and multiplication of new varieties, parental lines and hybrids. Hence, from of breeder point of view, study of qualitative characters is very useful to differentiate to various hybrids and their parental lines.

\section{References}

Bhanu, K.U. (2009). Genetic divergence in castor (Ricinus communis L.). M.Sc. (Agri.) Thesis (Unpublished), submitted to Acharya N. G. Ranga Agricultural University Agricultural College, Bapatla (Andhra Pradesh).

Chaudhari, B.A., Patel, M.P., Dharajiya, D.T. and Tiwari, K.K. (2019). Assessment of genetic diversity in castor (Ricinus communis L.) using microsatellite markers. Biosciences Biotechnology Research Asia, 16(1): 61-69. DOI: http://dx.doi.org/10.13005/bbra/2721.

Elena, M. and Edilyng, R. (2009). Study of the variability for racemes, fruits and seeds in castor germplasm. Journal of Revista Cientifica. 9 (4): 764-769.

Gourishankar, V., Rao, P.V.R. and Reddy, A.V. (2010). Inheritance of certain morphological characters and Fusarium wilt resistance in castor (Ricinus communis L). SABRAO Journal of Breeding and Genetics. 42 (2): 57-64.

Gupta, R. and Aggarwal, S. (2012). Variability studies in seed morphology of castor (Ricinus communis L.) collected from North-Eastern region of India. Indian Journal of Plant genetic resources. 26 (1): 82-85.

Lavanya, C. and Gopinath, V. (2008). Inheritance studies for morphological characters and sex expression in pistillate lines of castor (Ricinus communis L.). Indian Journal of Genetics and Plant Breeding. 68 (3): 275-282.

Rao, S.M., Bhanu, U.K., Rao, S.V. and Ahamed, L.M. (2014). The characterization of castor (Ricinus communis L.) germplasm for morphological traits. International Journal of Development Research. 4 (5): 1125-1128.

Rukhsar, S., Patel, M.P., Parmar, D.J., Kalola, A.D. and Kumar, S. (2017). Morphological and molecular diversity patterns in castor germplasm accessions. Industrial Crops and Products. 97: 316-323.

Sakure, A.A., Dhaduk, H.L., Mehta, D.R., Kavani, R.H. and Madariya, R.B. (2010). Genetics diversity analysis among castor (Ricinus communis L.) genotypes using morphological marker. 
Crop Improvement. 37 (2): 99-104.

Solanki, S.S. and Joshi, P. (2001). Inheritance study of some morphological traits in castor (Ricinus communis L.). The Indian Journal of Genetics and Plant Breeding. 61 (2): 136-139.

\section{How to cite this article:}

Chaudhari, B.A., M.P. Patel, J.A. Patel, R.R. Makwana, A.M. Patel and Patel, M.K. 2019. The Characterization of Castor (Ricinus communis L.) Genotypes for Morphological Traits. Int.J.Curr.Microbiol.App.Sci. 8(05): 2482-2492. doi: https://doi.org/10.20546/ijcmas.2019.805.293 